\title{
Left Second Rib Exostosis, Spinal Cord Compression and Left Upper Thoracic Scoliosis: A Rare Triad
}

\author{
Rohit Amritanand, Krishnan Venkatesh, Gabriel David Sundararaj
}

Spinal Disorders Surgery Unit, Department of Orthopaedics, Christian Medical College, Vellore, India

\begin{abstract}
Exostosis of the rib with neural foraminal extension as a cause of spinal cord compression and scoliosis has to the best of our knowledge not been reported. We describe a young male with hereditary multiple exostosis who presented with a spastic gait, lower limb weakness and a deformity of the upper back. Radiographic imaging revealed a lesion arising from the left second rib which was encroaching the spinal canal and a scoliotic deformity of the upper thoracic spine. Through a single $\mathrm{T}$ shaped posterior approach he underwent a decompressive laminectomy of $\mathrm{T} 1$ and $\mathrm{T} 2$ vertebra and excision of the lesion. The diagnosis of osteochondroma was confirmed by histopathological studies. He was followed up at one year when his neurological condition had returned to normal however the scoliosis had increased.
\end{abstract}

Key Words: Rib, Osteochondroma, Cord compression, Scoliosis, Excision

\section{Introduction}

Exostoses, also called Osteochondroma, account for $36 \%$ of all benign bone tumors and $8.5 \%$ of all bone tumors [1]. It has been estimated that up to $27 \%$ of patients with hereditary multiple exostosis may have an exostosis that encroaches into the spinal canal [2]. Neurological deficit usually occurs from exostosis that arise from vertebral body or lamina [1]. The occurrence of neural compression due to a rib exostosis is a rare event [3] and its presentation along with upper thoracic scoliosis has to the best of knowledge not been described. Herein we report the case and successful surgical management of a young man with hereditary multiple exostosis who presented in this very unusual manner.

\section{Case Report}

An 18-year-old gentleman presented to us with a feeling of weakness in both lower limbs, difficulty in walking and a deformity of his upper back for a period of one year. Examination of the spine revealed a left upper thoracic scoliosis and neurological examination elicited brisk deep tendon reflexes in the lower limbs with a positive Babinski response. Motor power, sensations and rectal sphinteric tone were normal. Physical examination of the limbs revealed multiple bony swellings around both knee joints. Plain roentgenogram of the dorsal spine revealed a left sided scoliotic deformity spanning from C7 to T5 measuring Cobb angle $26^{\circ}$ and a bosselated bony mass arising from the head of the left 2nd rib (Fig. 1). Plain roentgenogram of the extremities revealed multiple exostosis. The computed tomography (CT) scan (Figs. 2 and 3) confirmed that the lesion arose from the rib. On magnetic resonance image (MRI) the mass measured about $5 \times 3 \mathrm{~cm}$ and was arising from the left $2 \mathrm{nd}$ rib involving the transverse process, left lamina and the left pedicle of T1 vertebra. There was an extension of the lesion through C7-T1, and T1-T2 neural foramen which was displacing the cord to the right side and causing gross cord compression (Fig. 4). There were however no vertebral or

Received Mar 21, 2011; Revised May 12, 2011; Accepted May 12, 2011

Corresponding author: Rohit Amritanand, MS

Spinal Disorders Surgery Unit, Department of Orthopaedics, Christian Medical College,

Vellore, Tamil Nadu-632004, India

Tel: +91-41-6-2282020, Fax: +91-41-6-2232035, E-mail: rohit@cmcvellore.ac.in 
cord anomalies.

Through a single $\mathrm{T}$ shaped incision, the patient underwent an excision of the left 1st and 2nd rib and a hemilaminectomy of T1 and T2 vertebra. The lesion was seen to be an irregular mass with a bluish-grey cartilage cap (Fig. 5) which was occluding more than $50 \%$ of the canal at T1 level. It was excised in toto (Fig. 6).

Pathologically, the tumor specimen was found to have mature bone trabeculae covered by a cartiligenous cap with endochondral ossification. There was no evidence of malignant transformation and the final histopathological diagnosis was an osteochondroma.

The patient reported the onset of recovery of neurological symptoms 2 weeks after the surgery. At 12 month follow-up these had completely resolved and there was no evidence of recurrence. The scoliosis had however progressed to $38^{\circ}$ (Fig. 7).

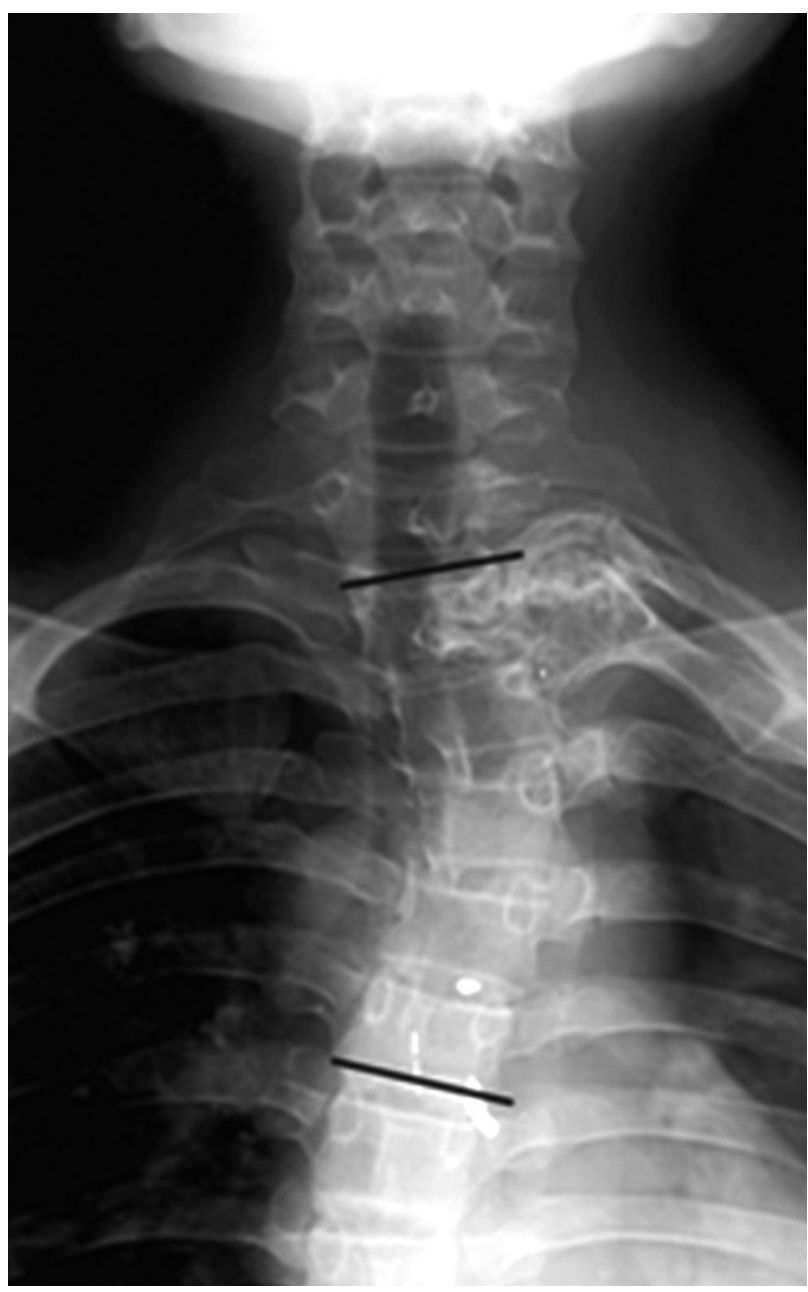

Fig. 1. Plain roentgenogram antero-posterior view of the Cervico thoracic spine showing the exostosis arising from the left 2 nd rib and the left thoracic scoliosis (Cobb angle $26^{\circ}$ ).

\section{Discussion}

Although rare there have been a few reports of rib exostosis, encroaching into the spinal canal, and leading onto neural deficit [3]. However, to the best of our knowledge there have been no reports of the aforementioned presentation being associated with a scoliotic deformity.

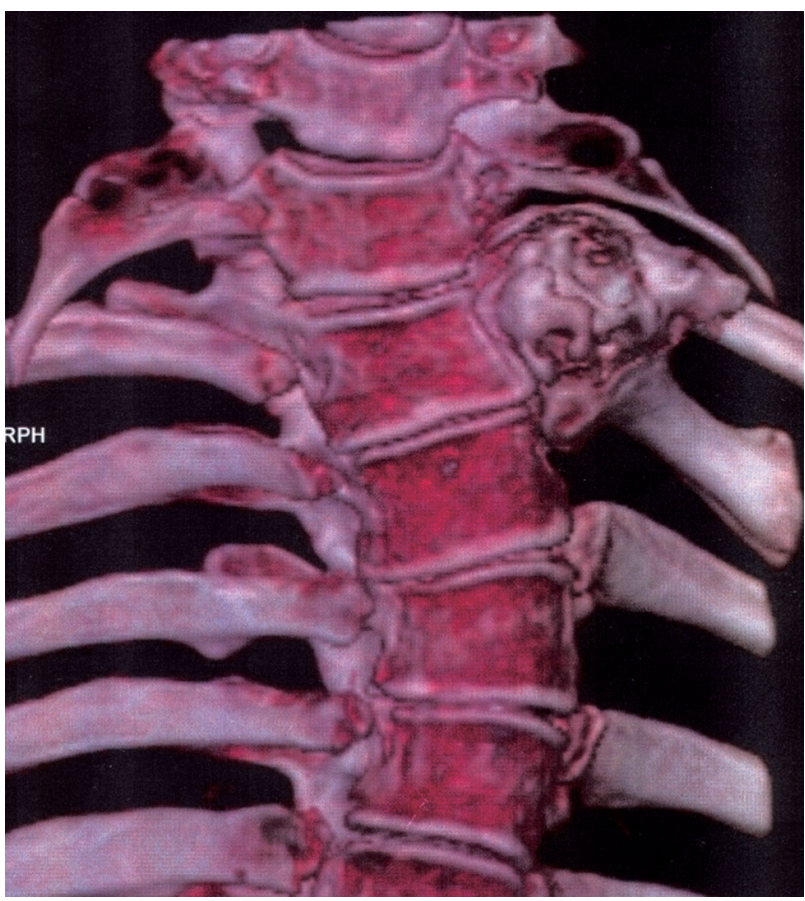

Fig. 2. Computed tomography (3D reconstruction) depicting the osteochondroma.

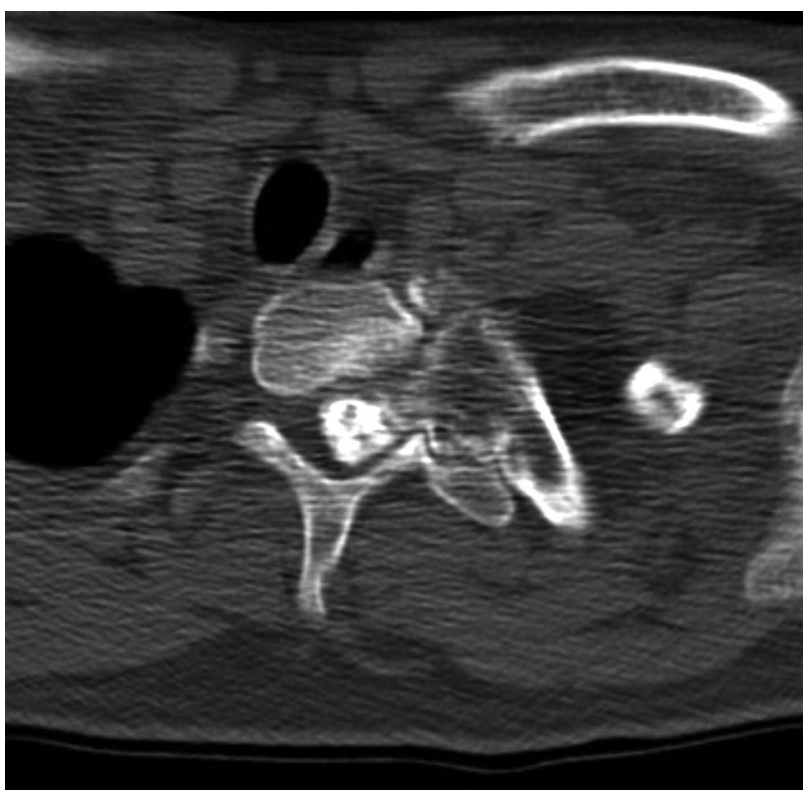

Fig. 3. Computed tomography (axial view) confirms that the osteochondroma arises from the rib and then encroaches more than $50 \%$ of the spinal canal. 
Exostoses that cause neurological symptoms usually arise from vertebral pedicles or lamina [4]. In this case however the CT scan clearly demonstrated that the exostosis arose from the rib head (Fig. 3). As described in other similar reports this patient underwent an excision of the lesion leading

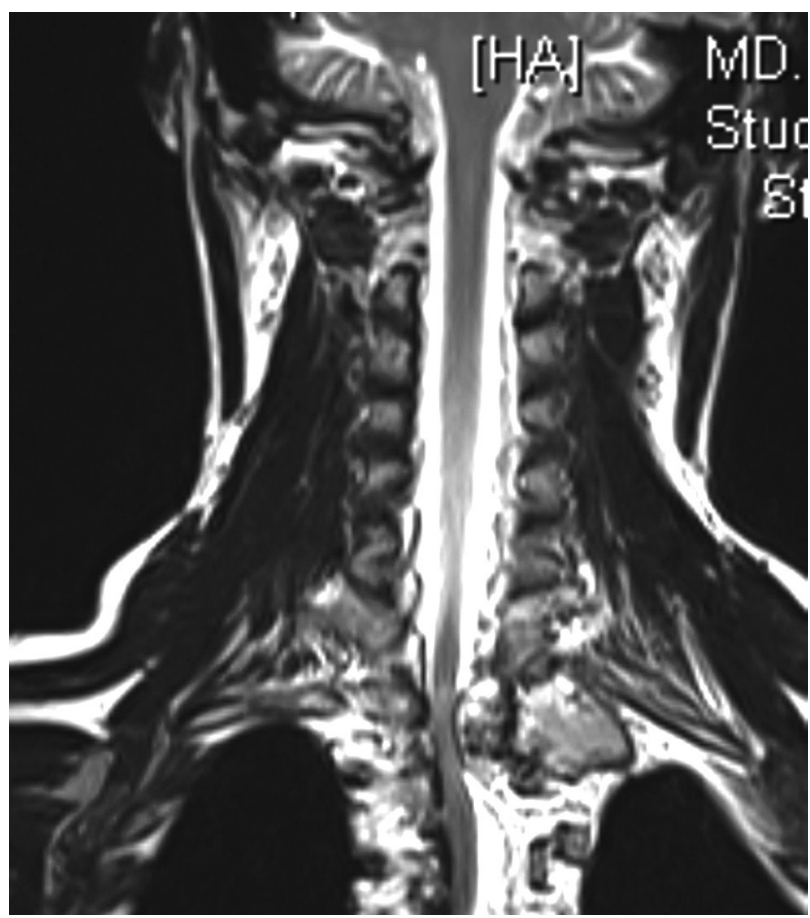

Fig. 4. Magnetic resonance image $\left(\mathrm{T}_{2}\right.$ weighted $)$ coronal view showing the lesion growing towards the midline. Note the normal anatomy of the vertebra.

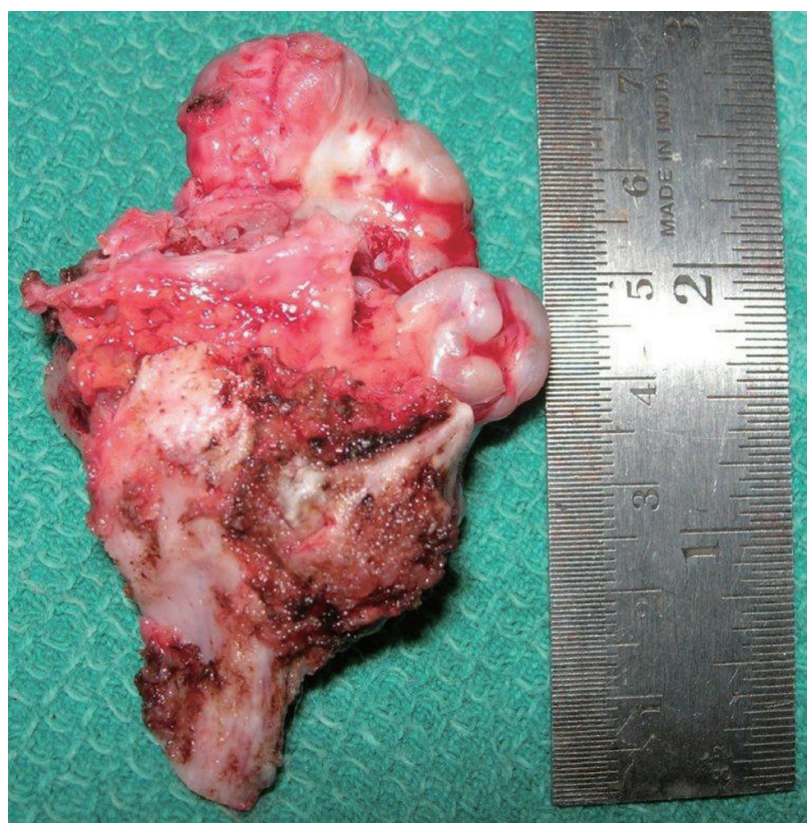

Fig. 5. Intraoperative specimen of the excised lesion removed in toto along with $2 \mathrm{~cm}$ of rib.

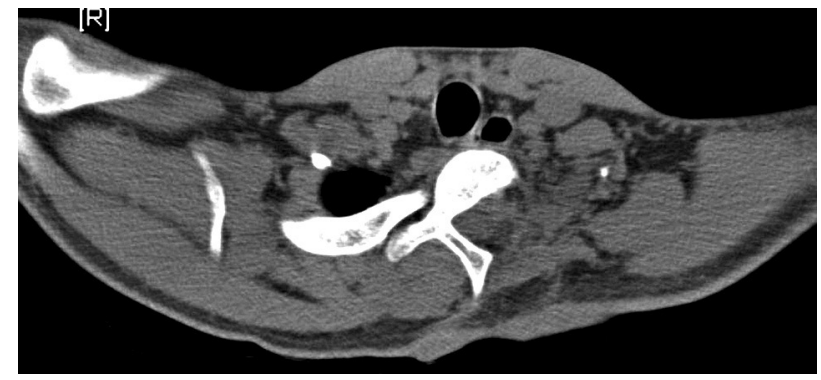

Fig. 6. Postoperative computed tomography (axial view) confirms the hemilaminectomy and that the lesion was completely excised.

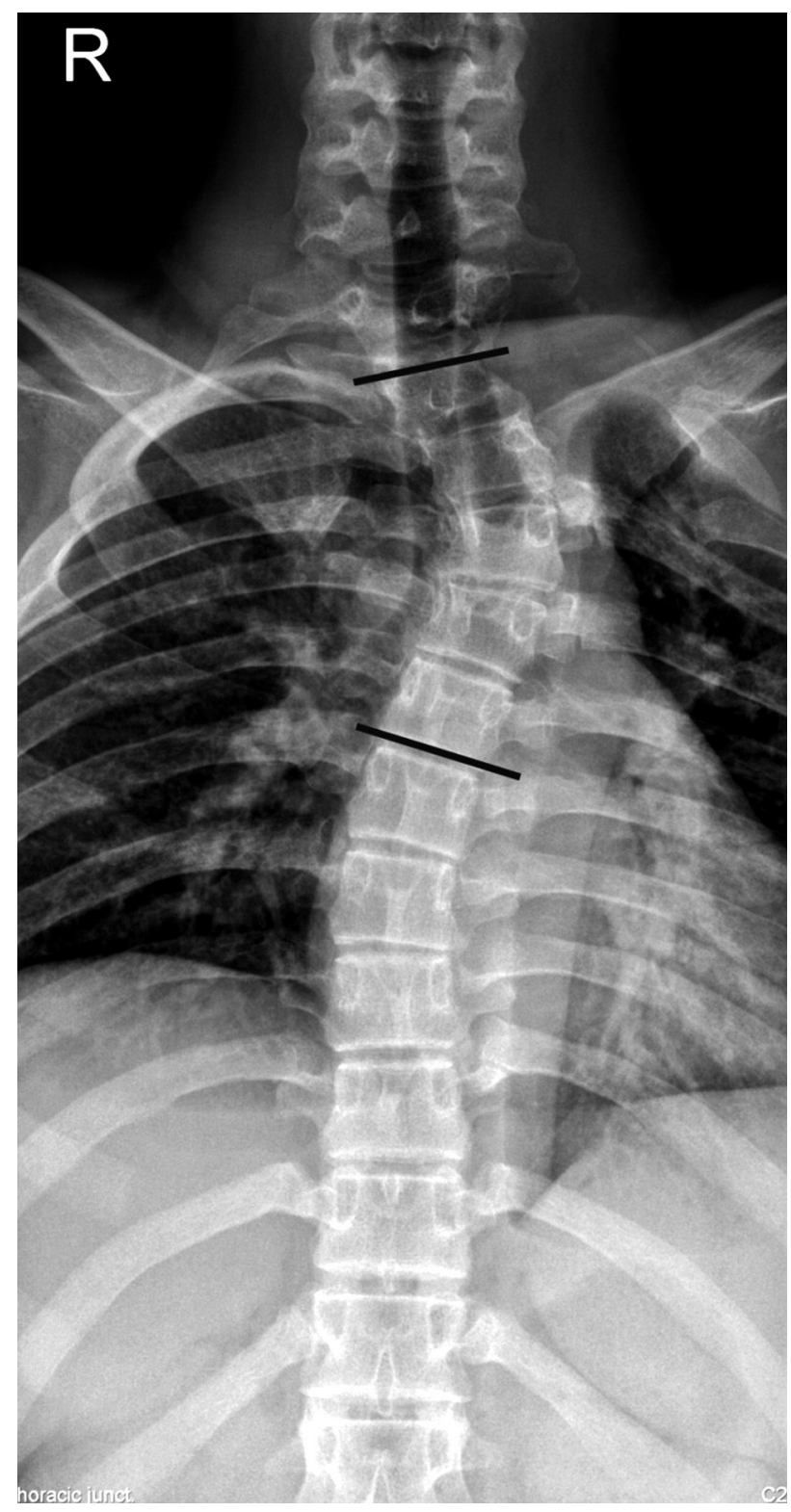

Fig. 7. Follow-up plain roentgenogram documents that the lesion has not recurred and the left thoracic scoliosis has progressed (Cobb angle $38^{\circ}$ ). 
onto a resolution of the neurological deficit. Early excision is warranted to prevent further neurological compromise [1] and to eliminate the low probability of malignant transformation [5].

The presence of an associated left upper thoracic scoliotic deformity in this patient was indeed perplexing. Though tumors like osteoid osteoma and osteoblastoma have been known to cause a pain-provoked scoliosis [6], these lesions, whether they arise for the rib or vertebra, have consistently arisen on the concave side of the curve [7]. The exostosis in this case arose from the ribs on the convex side. Furthermore it has been suggested that after removal of these lesions the scoliosis usually resolves [7] whereas in this case, a year after removal of the rib lesion, the deformity had infact progressed. Furthermore an osteochondroma is an unusual tumor to cause scoliosis. Infact a review of literature revealed only one report of a vertebral osteochondroma presenting as a thoracolumbar scoliosis [8] and another as an atypical spinal curve [9]. There have been no reported cases of a rib osteochondroma presenting as upper thoracic scoliosis. Though it has been stated that left thoracic curves are invariably associated with underlying pathology warranting 'full investigation' [10] this patient had no underlying disease of the spinal cord like a syrinx, Arnold Chiari malformation or any osseous vertebral anomalies (Fig. 2). Therefore in the absence of a identifiable cause it is maybe rational to suggest that this patient had a symptomatic rib exostosis along with a coincidental idiopathic scoliosis.

In the light of the resolution of his more distressing symptoms arising from neural compromise, the patient was not overly concerned about the deformity and even though the curve angle had increased to $38^{\circ}$ we felt that it was premature to surgically intervene. A similar reported case by Fiechtl et al. [9] had taken up to 2 years for resolution. Also Goldberg et al. [10] in a school screening program observed that left curve patterns were less likely to progress and less likely to require surgery. However the patient has been advised a regular follow-up.

In conclusion, the possibility of a rib exostosis may be kept in mind when patients with hereditary multiple exostosis present with neural compromise. The presence of an associated scoliosis in this case was probably coincidental.

\section{REFERENCES}

1. Mannoji C, Yamazaki M, Kamegaya M, Saisu T, Minami S, Takahashi K. Paraparesis caused by rib exostosis in a child with Down syndrome: a case report. Spine (Phila Pa 1976) 2008;33:E911-3.

2. Roach JW, Klatt JW, Faulkner ND. Involvement of the spine in patients with multiple hereditary exostoses. J Bone Joint Surg Am 2009;91:1942-8.

3. Tang WM, Luk KD, Leong JC. Costal osteochondroma. A rare cause of spinal cord compression. Spine (Phila Pa 1976) 1998;23:1900-3.

4. Giudicissi-Filho M, de Holanda CV, Borba LA, RassiNeto A, Ribeiro CA, de Oliveira JG. Cervical spinal cord compression due to an osteochondroma in hereditary multiple exostosis: case report and review of the literature. Surg Neurol 2006;66 Suppl 3:S7-11.

5. Kivioja A, Ervasti H, Kinnunen J, Kaitila I, Wolf M, Bohling T. Chondrosarcoma in a family with multiple hereditary exostoses. J Bone Joint Surg Br 2000;82:261-6.

6. Mehdian H, Summers B, Eisenstein S. Painful scoliosis secondary to an osteoid osteoma of the rib. Clin Orthop Relat Res 1988;(230):273-6.

7. Ransford AO, Pozo JL, Hutton PA, Kirwan EO. The behaviour pattern of the scoliosis associated with osteoid osteoma or osteoblastoma of the spine. J Bone Joint Surg Br 1984;66:16-20.

8. José Alcaraz Mexía M, Izquierdo Núñez E, Santonja Garriga C, María Salgado Salinas R. Osteochondroma of the thoracic spine and scoliosis. Spine (Phila $\mathrm{Pa}$ 1976) 2001;26:1082-5.

9. Fiechtl JF, Masonis JL, Frick SL. Spinal osteochondroma presenting as atypical spinal curvature: a case report. Spine (Phila Pa 1976) 2003;28:E252-5.

10. Goldberg CJ, Moore DP, Fogarty EE, Dowling FE. Left thoracic curve patterns and their association with disease. Spine (Phila Pa 1976) 1999;24:1228-33. 